\title{
Increased expression of advanced glycation end-products and their receptor, and activation of nuclear factor kappa-B in lacrimal glands of diabetic rats
}

Received: 2 February 2005 / Accepted: 12 July 2005 / Published online: 8 November 2005

(C) Springer-Verlag 2005

\begin{abstract}
Aims/hypothesis: To assess the involvement of the AGE-specific receptor (AGER, also known as RAGE) axis and nuclear factor kappa-B (NFKB, also known as NF-kappaB) activation in the development of lacrimal gland and tear film dysfunction in diabetes, the present study evaluated: (1) lacrimal gland and tear film alterations in diabetic rats; and (2) the expression of AGE, AGER and NFKB in ocular tissues of normoglycaemic and diabetic rats. Materials and Methods: Diabetes was induced in male Wistar rats with intravenous streptozotocin. Tear secretion parameters were measured and NFKB expression was evaluated in lacrimal glands of control and diabetic rats by western blot. Immunohistochemistry with confocal microscopy was used to assess AGE, AGER and NFKB expression in lacrimal glands of both groups. Results: Lacrimal gland weight and tear film volume were lower in diabetic than in control rats ( $p=0.01$ and 0.02 , respectively). IL1B and TNF concentrations in tears were higher in diabetic than in control rats ( $p=0.007$ and 0.02 , respectively). NFKB protein was identified in rat cornea, conjunctiva and lacrimal glands. AGE, AGER and NFKB expression were greater in lacrimal glands of diabetic than in those of control rats. Conclusions/interpretation: Diabetes induces significant alterations in rat lacrimal gland structure and secre-
\end{abstract}

M. Alves · V. C. Calegari - M. J. A. Saad · L. A. Velloso ·

E. M. Rocha

Laboratory of Clinical Physiopathology,

Department of Clinical Medicine,

School of Medicine,

State University of Campinas (UNICAMP),

Campinas, Brazil

D. A. Cunha

Institute of Biology,

State University of Campinas (UNICAMP),

Campinas, Brazil

E. M. Rocha $(\bowtie)$

Departamento de Oftalmologia, FMRP,

São Paulo University,

Av. Bandeirantes, 3900,

14049-900 Ribeirão Preto SP, Brazil

e-mail: emrocha@fmrp.usp.br tion. The higher expression of AGE, AGER and NFKB in lacrimal glands of diabetic rats suggests that these factors are involved in signalling and in subsequent inflammatory alterations related to dry eye in diabetes mellitus.

Keywords Advanced glycated end-products - Diabetes . Dry eye $\cdot$ Lacrimal gland $\cdot$ Nuclear factor kappa-B

Abbreviations AGER: AGE-specific receptor - CEL: $\mathrm{N}^{\varepsilon}$-carboxyethyl-lysine $\cdot \mathrm{CML}: \mathrm{N}^{\varepsilon}$-carboxymethyl-lysine NFKB1: nuclear factor kappa B 1

\section{Introduction}

Diabetes is associated with lacrimal gland and ocular surface dysfunctions related to dry eye syndrome [1-4]. Previous studies have suggested that chronic hyperglycaemia, corneal nerve alterations and disturbance in insulin action may play an important role in the development of such alterations, but the exact mechanisms that underlie these changes are not completely understood [5-8]. In accordance with the insulin action hypothesis, we have previously demonstrated that insulin receptor activation and other steps of insulin signalling pathways are impaired in lacrimal glands in animals with diabetes mellitus [9].

One of the major consequences of the hyperglycaemia and oxidative stress observed in diabetes is the formation of AGE as a result of the chemical reaction of carbohydrates with proteins. AGE binding to the AGE receptor (AGER, also known as RAGE), leads, among other events, to activation of the transcription factor nuclear factor kappa-B (NFKB1, also known as NF-kappaB), which has been proposed as a critical bridge between oxidant stress and gene expression [10].

NFKB1 is a heterodimer consisting of the subunits p50 and p65 complexed with the inhibitory subunit IkB. Its stimulation mechanism involves the degradation of the inhibitory subunit, IkB, freeing NFKB1 to translocate to the nucleus, where it regulates the expression of a large number of genes associated with cellular response to stress, such as tumour necrosis factor (TNF, also known as TNF-alpha), 
interleukin-1 beta (IL1B) and AGER [10]. Therefore, upon rapid accumulation of AGE in diabetic tissues, the upregulation and activation of AGER magnifies cellular perturbation in tissues affected by hyperglycaemia, leading to chronic complications in these tissues [10-13].

IL1B and TNF are known to influence the function of lacrimal gland tissues [14]. In addition, $I l 1 b$ and $T n f$ mRNA are increased in lacrimal gland and salivary glands of animal models with exocrine gland inflammatory dysfunction and on the ocular surface of patients with dry eye syndrome $[15,16]$. AGE-related mechanisms have been found to play a role in the pathogenesis of ocular diseases such as diabetic vitreous-retinopathy [17-19], age-related macular degeneration [20,21] and cataract [22-24]. Taken together, these data suggest that the possible mechanisms by which hyperglycaemia and oxidative stress act in diabetes-related lacrimal gland dysfunction may involve the formation of AGE and activation of NFKB1 in the lacrimal gland, leading to the expression of pro-inflammatory cytokines such as IL1B and TNF in this tissue.

Streptozotocin has been used for decades to induce diabetes in animal models. However, the lacrimal gland and ocular surface alterations that are related to diabetes have not been completely characterised in this model $[9,25,26]$.

Therefore, the objectives of the present study were: (1) to characterise diabetes-related alterations in lacrimal glands and tears of streptozotocin-induced diabetic rats; (2) to determine whether lacrimal gland and ocular surface tissues express NFKB1, AGE and AGER; and (3) to evaluate the influence of diabetes on the expression of AGE, AGER and NFKB1 in the lacrimal gland.

\section{Materials and methods}

\section{Animal model}

Eight-week-old male Wistar rats (Rattus norvegicus) were obtained from the State University of Campinas Animal Breeding Centre, Campinas, São Paulo, Brazil. Animals were given free access to standard rodent chow and water. Food was withdrawn $12 \mathrm{~h}$ before the experiments and diabetes was induced with a single dose of streptozotocin (Sigma, St Louis, MO, USA), $60 \mathrm{mg} / \mathrm{kg}$ body weight, diluted in $1 \mathrm{ml}$ citrate buffer $0.01 \mathrm{~mol} / \mathrm{l}$ administered through the caudal vein. Controls were injected with citrate buffer alone. Comparative studies of the two groups were performed 10 weeks after diabetes induction.

All experimental procedures adhered to the "Principles of laboratory animal care" (NIH publication no. 85-23), and were approved by the University's committee on animal experimentation.

\section{Serum glucose determination}

Four weeks after treatment, rats were anaesthetised with an intraperitoneal injection of sodium thiopental, $50 \mathrm{mg} / \mathrm{kg}$ (Cristália, Itapira, SP, Brazil), and blood samples were col- lected from streptozotocin-treated and control animals $(n=15$ per group) by puncture of a caudal vein 10 to 15 min later, as soon as anaesthesia was assured by the loss of foot and corneal reflexes. Samples were analysed by the colorimetric oxidase glucose method (Labtest, Lagoa Santa, MG, Brazil), and absorbance values, determined by spectrophotometry (U-2000 spectrophotometer; Hitachi, Japan), were compared to a known glucose concentration curve.

Determination of tear volume and IL1B and TNF content in the tear film

Tear volume was measured in both study groups $(n=10$ per group) 10 weeks after streptozotocin treatment. Under the same anaesthetic conditions, tears were collected with the use of micropipettes (Eppendorf Research, Hamburg, Germany) from the lacrimal meniscus, while trying to collect the whole tear volume in one take and also to avoid stimuli.

IL1B and TNF were measured in tears ( $n=5$ per group) from diabetic and control rats using an ELISA kit for IL1B and TNF (Pierce Endogen, Rockford, IL, USA), according to manufacturer's instructions.

Assay of peroxidase activity in lacrimal gland

Peroxidase activity in lacrimal gland of diabetic and control rats ( $n=5$ per group) was determined 10 weeks after streptozotocin injection. As previously described, peroxidase is a marker enzyme well suited for the study of protein export in the lacrimal gland system [27]. Lacrimal gland samples were homogenised in Hanks' solution at $4^{\circ} \mathrm{C}$ and centrifuged at $10,000 \times g$ for $8 \mathrm{~min}$. The protein concentration of the supernatant was measured by the biuret dye method (Labtest), to obtain a standard concentration of $100 \mu \mathrm{g} / \mathrm{ml}$ protein in each sample. $\mathrm{H}_{2} \mathrm{O}_{2}$ was added at a final concentration of $2.3 \mathrm{mmol} / 1$ to each experimental and control sample. Aliquots were collected at 0, 5, 10, 20, 30, 40 and $60 \mathrm{~min}$ and peroxidase activity was measured using a colorimetric reaction (Glucose GODPAP; Laborlab, Guarulhos, SP, Brazil) and compared to a standard $\mathrm{H}_{2} \mathrm{O}_{2}$ curve. Values were fitted with single exponential decay curves according to the formula: $\left[\mathrm{H}_{2} \mathrm{O}_{2}\right] .(t)=[\mathrm{H} 2 \mathrm{O} 2]_{t=0} \times \mathrm{e}^{-\mathrm{kt}}$, where the peroxidase activity of each sample is represented by the $k$ value (decay constant) or the rate of decrease of $\mathrm{H}_{2} \mathrm{O}_{2}$ concentration per minute obtained [28].

Evaluation of the expression of NFKB1 on the ocular surface and in lacrimal gland

Western blot studies to evaluate the expression of NFKB1 using rabbit polyclonal anti-NFKB1 subunit p65 (Santa Cruz Biotechnologies, Santa Cruz, CA, USA) were performed on whole-cell lysates from cornea, conjunctiva and lacrimal gland obtained from 8-week-old rats, as well as in nuclear and cytoplasmic extracts of both study groups as previously described [9]. In summary, samples were 
homogenised and protein quantification was performed as mentioned above after centrifugation. Samples were treated with Laemmli buffer, and equal amounts of protein per sample (ranging from 33 to $300 \mu \mathrm{g}$ ) were subjected to SDSPAGE (10\% Tris-acrylamide) in a Bio-Rad miniature slab gel apparatus (Miniprotean; Bio-Rad Laboratories, Richmond, CA, USA), in parallel with pre-stained protein standards and $\beta$-mercaptoethanol (Bio-Rad, Hercules, CA, USA). Proteins were then electro-transferred from the gel to an ECL nitrocellulose membrane (Hybond; Amersham, Buckinghamshire, UK) for $2 \mathrm{~h}$ at $120 \mathrm{~V}$ in a miniature transfer apparatus (Bio-Rad). After blocking, the membranes were incubated overnight with rabbit polyclonal anti-NFKB1 subunit p65 (Santa Cruz) at a concentration of $0.4 \mu \mathrm{g} / \mu \mathrm{l}$ in a buffer with $3 \% \mathrm{BSA}$, and then washed three times as described above. The blots were then incubated with ${ }^{125}$ I-labelled protein A (Amersham) and detected by autoradiography.

Determination of the expression of NFKB1 in nuclear and cytoplasmic extracts of lacrimal gland

Nuclear and cytoplasmic extracts were obtained from the exorbital lacrimal gland of diabetic and control rats $(n=5$ per group) collected under thiopental anaesthesia 5 and 10 weeks after the induction of diabetes, as previously described [29]. In summary, lacrimal gland homogenates were centrifuged at $2,000 \times \mathrm{g}$ for $10 \mathrm{~min}$ at $4^{\circ} \mathrm{C}$ in a centrifuge (5804R; Eppendorf). The pellet was then resuspended in buffer A, and centrifuged again at the same speed and for the same time. The supernatant corresponded to the cytoplasmic extract. The pellet was then resuspended in a buffer B containing $420 \mathrm{mmol} / 1 \mathrm{NaCl}, 10 \mathrm{mmol} / \mathrm{l} \mathrm{KCl}$, $20 \mathrm{mmol} / 1 \mathrm{HEPES}, \mathrm{pH}$ 7.9, 20\% glycerol, $1 \mathrm{mmol} / \mathrm{l} \mathrm{DTT}$, $1 \mathrm{mmol} / 1 \mathrm{Na}_{3} \mathrm{VO}_{4}$ (Sigma), and $0.8 \mathrm{mg}$ aprotinin. The resuspended material was then sonicated 10 times in a homogeniser (Potter-Elvehjem; Kimble Kontes, Vineland, NJ, USA) for $30 \mathrm{~min}$, and then centrifuged at $16,000 \times \mathrm{g}$ for 30 min. The supernatant corresponded to the nuclear extract. Again, protein quantification was performed and equal amounts of protein $(150 \mu \mathrm{g})$ were used for each sample in the western blot studies with anti-NFKB1 subunit p65 (Santa Cruz).

Images of developed autoradiographs were scanned, and band intensities were quantified by optical densitometry using image analysis software (Scion Image Analysis Software, Scion, Frederick, MD, USA).

Expression and immunochemical localisation of NFKB1, AGE and AGER in the lacrimal gland and cornea of diabetic and control rats

The expression of NFKB1, AGE and AGER was evaluated in lacrimal gland and cornea of diabetic and control rats $(n=5$ per group) using immunohistochemistry and confocal mi- croscopy. Lacrimal gland and cornea were excised, some of them were embedded in OCT compound (Sakura Fine Tek, Torrance, CA, USA), frozen in liquid nitrogen, and stored at $-80^{\circ} \mathrm{C}$, while others were fixed in buffered formalin $(10 \%)$ and immersed in paraffin. Tissue specimens were cut into $6 \mu \mathrm{m}$ sections at $-20^{\circ} \mathrm{C}$ and transferred to poly-L-lysine precoated glass slides (Perfecta, São Paulo, SP, Brazil). Slides of paraffin sections were submitted to haematoxylin-eosin staining.

The slides used for imunohistochemistry were exposed to acetone for $10 \mathrm{~min}$, washed in PBS $(0.1 \mathrm{~mol} / \mathrm{l}$ sodium phosphate, $0.15 \mathrm{~mol} / \mathrm{l}$ sodium chloride, $\mathrm{pH}$ 7.4) and exposed to $3 \%$ BSA (Sigma) solution for $1 \mathrm{~h}$ at $22^{\circ} \mathrm{C}$ to reduce nonspecific protein binding. The sections were incubated overnight with the following primary antibodies: anti-NFKB1 rabbit polyclonal antibody (Santa Cruz Biotechnologies) specific for the $\mathrm{p} 65$ subunit, anti-AGE mouse monoclonal antibody 6D12 specific for $\mathrm{N}^{\varepsilon}$-carboxymethyl-lysine (CML) and $\mathrm{N}^{\varepsilon}$-carboxyethyl-lysine (CEL) [30] (Research Diagnosis, Flanders, NJ, USA), or anti-AGER rabbit polyclonal antibody (Santa Cruz), at a concentration of $4 \mu \mathrm{g} / \mu \mathrm{l}$ with $1 \%$ BSA in PBS. The sections were then washed in PBS and incubated for $2 \mathrm{~h}$ with an anti-rabbit or anti-mouse IgG antibody conjugated with fluorescein isothiocyanate (Jackson Immunoresearch Laboratories, West Grove, PA, USA) at a concentration of $375 \mu \mathrm{g} / \mu \mathrm{l}$ in a $1 \%$ BSA solution. Sections were then washed and counterstained with phalloidin (Sigma) concentrated to $0.1 \mu \mathrm{g} / \mu \mathrm{l}$ for $45 \mathrm{~min}$ in a dark chamber. The slides were covered with Vectashield (Vector Laboratories, Burlingame, CA, USA) and a cover slip. Controls for immunospecificity were included in all experiments by omitting the primary antibody and replacing it with PBS and matching concentrations of normal rabbit or mouse serum. Photographic documentation was performed using a confocal microscope (Axiovert 200 M; Zeiss, Wetzlar, Germany) and the same exposure parameters for diabetic and control samples. Image analysis was done with LSM 510 V 3.2 software (Zeiss).

\section{Statistical analysis}

Data are expressed as means \pm SEM. Comparisons were made using the Mann-Whitney $U$-test (Statview; Abacus, Berkeley, CA USA). Densitometric values are expressed as a percentage of the mean value obtained for the control group, which was defined as $100 \%$ in each experimental assay. The level of significance used was $p<0.05$.

\section{Results}

Characterisation of lacrimal gland changes in streptozotocin-induced diabetic rats

Four weeks after streptozotocin treatment, rats were markedly hyperglycaemic compared to citrate buffer-treated con- 


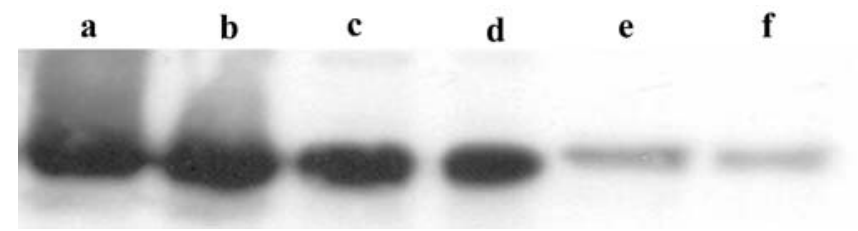

Fig. 1 NFKB1 p65 expression in lacrimal gland (LG), cornea $(C O)$ and conjunctiva $(C J)$ of 8 -week-old Wistar rats. The findings are representative of three independent experiments with three animals each. Tissues were collected and whole cell lysates analysed by western blot. Molecular weight markers were run in parallel. Lane $a$ : $L G 300 \mu \mathrm{g}$ of loaded protein; lane b: $L G 150 \mu \mathrm{g}$ of protein; lane c: CO $200 \mu \mathrm{g}$ of protein; lane d: CO $100 \mu \mathrm{g}$ of protein; lane e: CJ $66 \mu \mathrm{g}$ of protein; lane $f: C J 33 \mu \mathrm{g}$ of protein

trols, with the two groups presenting serum glucose of $31.9 \pm$ 5.4 and $9.6 \pm 1.1 \mathrm{mmol} / \mathrm{l}$, respectively ( $n=15$ per group). Mean body weight was $256.00 \pm 8.62 \mathrm{~g}$ in diabetic rats and $349.00 \pm 7.79 \mathrm{~g}$ in controls $(n=5$ per group) $(p=0.01)$.

In order to characterise the alterations induced by diabetes in lacrimal gland and tears, the studies described below were performed.

Mean lacrimal gland weight was $70 \pm 20 \mathrm{mg}$ in diabetic rats and $130 \pm 10 \mathrm{mg}$ in controls $(n=5$ per group) $(p=0.01)$, and the lacrimal gland weight : body weight ratio was $0.26 \pm$ $0.03 \mathrm{mg} / \mathrm{g}$ in diabetic rats and $0.38 \pm 0.03 \mathrm{mg} / \mathrm{g}$ in controls $(p=0.02)$. Ten weeks after streptozotocin treatment, the tear volume was $0.97 \pm 0.62 \mu \mathrm{l}$ in diabetic rats and $1.64 \pm 0.93 \mu \mathrm{l}$ in control rats $(n=10$ per group) ( $p=0.02)$.

Peroxidase levels were slightly higher in lacrimal gland of diabetic rats, as demonstrated by the peroxidase activity decay determined at the same time-point in samples of both groups. This finding, however, did not achieve significance. The decay of $\mathrm{H}_{2} \mathrm{O}_{2}$ over $1 \mathrm{~h}$ was $138 \pm 46 \mu \mathrm{mol} / \mathrm{l} \mathrm{min}$ in diabetic rats and $69 \pm 23 \mu \mathrm{mol} / 1 \mathrm{~min}$ in control rats $(n=5$ per group) $(p=0.34)$.

\section{Determination of IL1B and TNF in tears}

The inflammatory aspects of diabetes in tears were evaluated by comparing pro-inflammatory cytokines in both groups. In tears collected 10 weeks after streptozotocin treatment IL1B values were $10.12 \pm 1.24 \mathrm{ng} / \mathrm{ml}$ in diabetic versus $4.26 \pm 0.18 \mathrm{ng} / \mathrm{ml}$ in control rats $(p=0.007)$. The values for TNF were: $160.92 \pm 35.89 \mathrm{pg} / \mathrm{ml}$ in diabetic rats and $57.32 \pm 12.68 \mathrm{pg} / \mathrm{ml}$ in control rats $(p=0.02)$.

NFKB1 expression in control and diabetic lacrimal gland and ocular surface tissues

Western blot analysis was performed to confirm the presence of NFKB1 in lacrimal gland and on the ocular surface, and to compare its expression in lacrimal gland of diabetic versus control rats.

Expression of NFKB1 proteins was detected in the cornea, conjunctiva and lacrimal gland of 8-week-old control rats (Fig. 1). The comparative expression of NFKB1 in nuclear and cytoplasmic extracts of lacrimal gland control and diabetic rats 5 weeks after streptozotocin injection was similar ( $p=0.99$ for both extracts; data not shown). Ten weeks after streptozotocin injection, NFKB1 protein was expressed in higher levels in nucleus and cytoplasmic extracts of diabetic animals than in those from control animals ( $n=3$ per group) ( $p=0.02$ and $p=0.02$, respectively). These results were confirmed in three independent experiments (Fig. 2a,b).

Histological evaluation and immunochemical localisation of NFKB, AGE and AGER in lacrimal gland

Histological comparison between diabetic and control lacrimal gland revealed a similar distribution of epithelial and connective tissue, as well as similar acini size and dis-
Fig. 2 Effect of streptozotocininduced diabetes on NFKB1 p65 expression in nuclear (a) and cytoplasmic (b) extracts of lacrimal gland. Ten weeks after streptozotocin injection, lacrimal glands were excised and nuclear and cytoplasmic extracts ( $n=3$ animals per group) were analysed by western blot using an anti-NFKB1 antibody specific for the p65 subunit. Values are represented as means \pm SEM. Values for the control group were defined as $100 \%$, and those for diabetic animals are expressed as a percentage of this. Results are representative of three independent experiments. Higher expression of NFKB1 p65 was detected in nuclear and cytoplasmic extracts of diabetic animals $(p=0.02)$

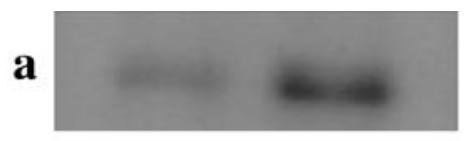

Control

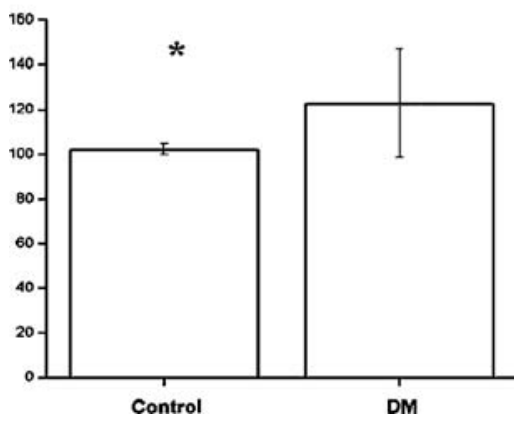

b

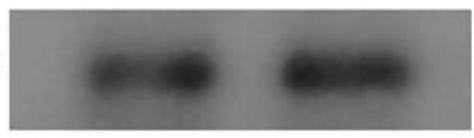

Control

DM

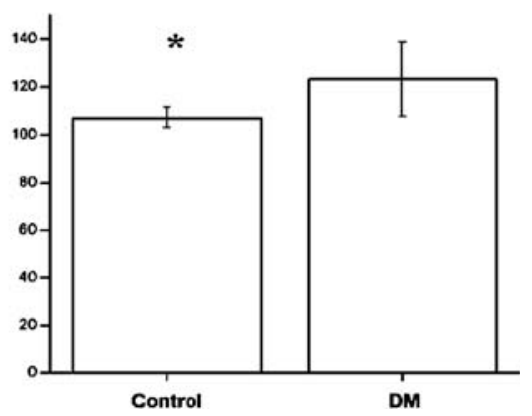


Fig. 3 Representative immunohistochemical confocal microphotographs of lacrimal glands from control and diabetic rats. Green staining: $(\mathbf{a}, \mathbf{b})$ NFKB1 p65 in control rats and diabetic rats respectively; (c, d) AGE antibody $6 \mathrm{D} 12$ specific for $\mathrm{N}^{\varepsilon}$. carboxymethyl lysine $(C M L)$ and $\mathrm{N}^{\varepsilon}$-carboxyethyl-lysine $(C E L)$ in control and diabetic rats respectively; (e, f) AGER in control and diabetic rats. Red: slides were counterstained with phalloidin, indicating the localisation of actin in the acinar or ductal cell membrane. Micrographs are representative of two independent experiments with five animals per group. Exposure parameters were constant throughout the experiments. Bar: $20 \mu \mathrm{m}$
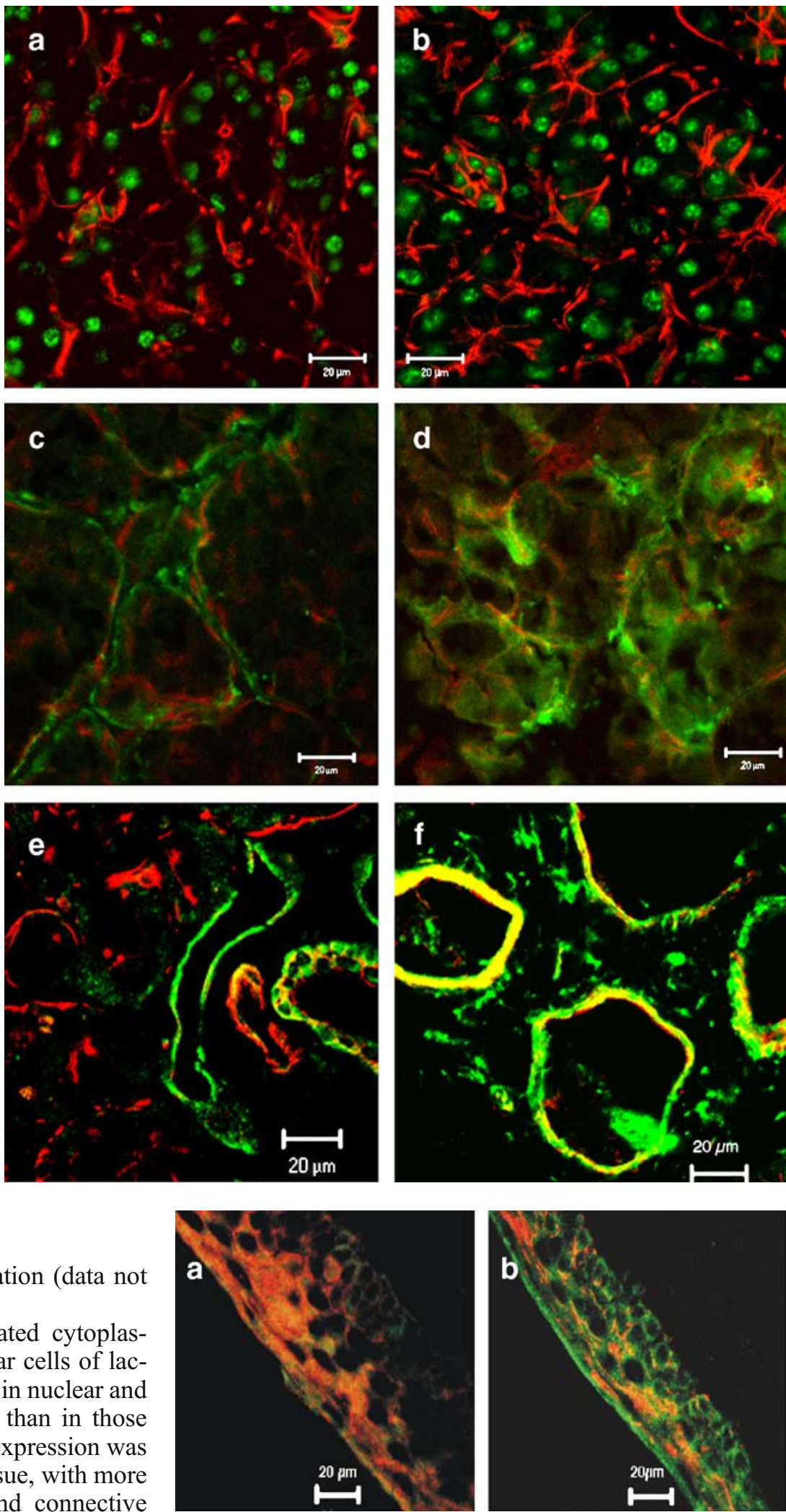

Fig. 4 Representative immunohistochemical confocal microphotographs demonstrating AGER staining (green) in the cornea of control (a) and diabetic (b) rats. Slides were counterstained with phalloidin (red) indicating the localisation of actin in the epithelial membrane. Selected micrographs are representative of two independent experiments with five animals per group. Exposure parameters were constant throughout the experiments 
brane and cytoplasm; it was more intensely expressed in diabetic than in control rats (Fig. 4a,b).

\section{Discussion}

Ocular surface complications associated with diabetes include dry eye symptoms [1-5]. However, the cascade of events that lead to alterations of tear film and lacrimal gland function in diabetes is not completely understood. Various recent reports have described increased AGE accumulation, AGER expression and NFKB1 activation in the organs of diabetic animals, and have postulated the pathophysiological relevance of these cellular events in diabetic complications such as diabetic retinopathy [10, 13]. Here we studied whether the AGE-AGER axis contributes to lacrimal gland and tear film disease in a streptozotocin-induced diabetes animal model.

Using this model, we first demonstrated alterations that indicated the presence of lacrimal gland and ocular film dysfunction in diabetic rats, such as a significantly lower tear volume and a significantly lower lacrimal gland weight: body weight ratio in diabetic rats compared to controls. These changes are analogous to those described in similar animal models, and in humans suffering from dry eye syndrome $[1-3,16,31]$.

Peroxidase activity was slightly higher in diabetic lacrimal gland. This finding was surprising and different from that observed in ageing models [32]. However, two different recent works observed that streptozotocin-induced diabetes [33] and androgen or thyroid hormone suppression [34] in fact lead to higher peroxidase activity in lacrimal glands than that seen in controls with intact hormone function.

Next, we demonstrated that NFKB1 p65 is expressed in lacrimal gland and ocular tissues of control rats and, more importantly, that this expression is significantly increased in nuclear and cytoplasmic lacrimal gland extracts from diabetic animals compared to controls. These results were confirmed in western blot and immunohistochemistry studies and were in accordance with our initial hypothesis of an involvement of NFKB1 in the lacrimal gland dysfunction observed in diabetes.

To further explore this hypothesis, we then studied the expression of AGE and AGER, two mediators of the cellular events that lead to the activation of NFKB1, in lacrimal gland of diabetic and control rats. In fact, AGE and AGER expression were increased in lacrimal glands of diabetic compared to control rats, which suggests a relationship between the AGE-AGER axis, which involves the expression of NFKB1, and the lacrimal gland dysfunction observed in diabetic animals. As recently reported, the antibody used (6D12) in the present study recognises two antigenic structures of AGE: CML and CEL, both previously identified in ageing and diabetes-related diseases [30].

We observed an increase in NFKB1 not only in the nucleus, but also in the cytoplasm of lacrimal gland. As previously demonstrated, the higher levels in the cyto- plasm, within the context of sustained activation of NFKB1 as seen in diabetes, imply a higher de novo synthesis of this transcription factor [11]. Furthermore, the occurrence of new NFKB1 synthesis and its higher presence in the nucleus without the inhibitory subunit IkB suggest that AGE/ AGER interaction leads to NFKB1 activation, sustained oxidative stress and pro-inflammatory cytokine transcription, thus mediating tissue damage and impaired lacrimal gland function, as previously attributed to IL1B in autoimmune xerophthalmia [14].

It is also possible that $\mathrm{S} 100 /$ calgranulin, a pro-inflammatory ligand of AGER that is involved in pathological findings in other tissues of diabetes mellitus, plays a role in lacrimal gland alterations, but further investigation is needed on this. [35].

The marked staining for AGER in ductal epithelial cells, which was greater than in other lacrimal gland cells, was surprising and is not clearly understood. Moreover, despite its previous description in a range of other cells [23], it was not possible in the present work, using standard techniques like western blot, to achieve the same comparative intensity in control and diabetic lacrimal gland as was achieved in that study.

Taken together, the alterations in lacrimal gland and tear film observed by us in an animal model of diabetes allow us to postulate that the pathogenesis of ocular surface dysfunction, and specifically of the dry eye syndrome observed in diabetes mellitus, may be associated in part with the accumulation of AGE and activation of NFKB1 induced by chronic hyperglycaemia, an association that has been previously demonstrated in other ocular tissues [1719, 31].

Due to the in vivo model adopted and the magnitude of the molecular differences observed, it is difficult to predict the weight of these events comparative to other changes observed in chronic diabetes, such as osmotic fluid changes and vascular and neurotrophic input reduction in the mechanism of lacrimal gland dysfunction in diabetes.

Previous studies with animal models have indicated a protective effect of pyridoxamine or aminoguanidine, two anti-AGE agents, against renal disease [36] and retinopathy [37] in the context of chronic hyperglycaemia and AGE accumulation. In addition, a clinical study indicated that antioxidant therapy can improve some parameters on the ocular surface of diabetic patients [38]. However, it remains to be clarified whether symptoms associated with the lacrimal gland and/or tear film dysfunction observed in diabetic patients could be improved or reversed by antiAGE strategies. Future studies addressing these issues could lead to specific therapies for tear film and ocular surface alterations in diabetes.

Acknowledgements Supported by Fundação de Amparo à Pesquisa do Estado de São Paulo (FAPESP, Foundation to Support Research of São Paulo State) and Conselho Nacional de Desenvolvimento Científico e Tecnológico (CNPq, National Council of Scientific and Technological Development). 


\section{References}

1. Ramos-Remus C, Suarez-Almazor M, Russell AS (1994) Low tear production in patients with diabetes mellitus is not due to Sjogren's syndrome. Clin Exp Rheumatol 12:375-380

2. Seifart U, Strempel I (1994) The dry eye and diabetes mellitus. Ophthalmologe 91:235-239

3. Goebbels M (2000) Tear secretion and tear film function in insulin dependent diabetics. Br J Ophthalmol 84:19-21

4. Dogru M, Katakami C, Inoue M (2001) Tear function and ocular surface changes in noninsulin-dependent diabetes mellitus. Ophthalmology 108:586-592

5. Hyndiuk RA, Kazarian EL, Schultz RO, Seideman S (1977) Neurotrophic corneal ulcers in diabetes mellitus. Arch Ophthalmol 95:2193-2196

6. Ishida N, Rao GN, del Cerro M, Aquavella JV (1984) Corneal nerve alterations in diabetes mellitus. Arch Ophthalmol 102: $1380-1384$

7. Azar DT, Spurr-Michaud SJ, Tisdale AS, Gipson IK (1992) Altered epithelial-basement membrane interactions in diabetic corneas. Arch Ophthalmol 110:537-540

8. McNamara NA, Brand RJ, Polse KA, Bourne WM (1998) Corneal function during normal and high serum glucose levels in diabetes. Invest Ophthalmol Vis Sci 39:3-17

9. Rocha EM, de MLMH, Carvalho CR et al (2000) Characterization of the insulin-signaling pathway in lacrimal and salivary glands of rats. Curr Eye Res 21:833-842

10. Singh R, Barden A, Mori T, Beilin L (2001) Advanced glycation end-products: a review. Diabetologia 44:129-146

11. Bierhaus A, Schiekofer S, Schwaninger M et al (2001) Diabetes-associated sustained activation of the transcription factor nuclear factor-kappaB. Diabetes 50:2792-2808

12. Portero-Otin M, Pamplona R, Bellmunt MJ et al (2002) Advanced glycation end product precursors impair epidermal growth factor receptor signaling. Diabetes 51:1535-1542

13. Vlassara H, Bucala R, Striker L (1994) Pathogenic effects of advanced glycosylation: biochemical, biologic, and clinical implications for diabetes and aging. Lab Invest 70:138-151

14. Zoukhri D, Hodges RR, Byon D, Kublin CL (2002) Role of proinflammatory cytokines in the impaired lacrimation associated with autoimmune xerophthalmia. Invest Ophthalmol Vis Sci 43:1429-1436

15. Rocha EM, Wickham LA, Huang Z et al (1998) Presence and testosterone influence on the levels of anti- and pro-inflammatory cytokines in lacrimal tissues of a mouse model of Sjogren's syndrome. Adv Exp Med Biol 438:485-491

16. Solomon A, Dursun D, Liu Z et al (2001) Pro- and antiinflammatory forms of interleukin-1 in the tear fluid and conjunctiva of patients with dry-eye disease. Invest Ophthalmol Vis Sci 42:2283-2292

17. Stitt AW, Moore JE, Sharkey JA et al (1998) Advanced glycation end products in vitreous: structural and functional implications for diabetic vitreopathy. Invest Ophthalmol Vis Sci 39:2517-2523

18. Kalfa TA, Gerritsen ME, Carlson EC et al (1995) Altered proliferation of retinal microvascular cells on glycated matrix. Invest Ophthalmol Vis Sci 36:2358-2367

19. Moore TC, Moore JE, Kaji Y et al (2003) The role of advanced glycation end products in retinal microvascular leukostasis. Invest Ophthalmol Vis Sci 44:4457-4464

20. Howes KA, Liu Y, Dunaief JL et al (2004) Receptor for advanced glycation end products and age-related macular degeneration. Invest Ophthalmol Vis Sci 45:3713-3720
21. Hammes HP, Hoerauf H, Alt A et al (1999) $N$ (epsilon) (carboxymethyl)lysin and the AGE receptor RAGE colocalize in age-related macular degeneration. Invest Ophthalmol Vis Sci 40:1855-1859

22. Ahmed N, Thornalley PJ, Dawczynski J et al (2003) Methylglyoxal-derived hydroimidazolone advanced glycation end-products of human lens proteins. Invest Ophthalmol Vis Sci 44:5287-5292

23. Das BK, Sun TX, Akhtar NJ et al (1998) Fluorescence and immunochemical studies of advanced glycation-related lens pigments. Invest Ophthalmol Vis Sci 39:2058-2066

24. Saxena P, Saxena AK, Cui XL et al (2000) Transition metalcatalyzed oxidation of ascorbate in human cataract extracts: possible role of advanced glycation end products. Invest Ophthalmol Vis Sci 41:1473-1481

25. Rakieten N, Rakieten ML, Nadkarni MV (1963) Studies on the diabetogenic action of streptozotocin (NSC-37917). Cancer Chemother Rep 29:91-98

26. Junod A, Lambert AE, Orci L et al (1967) Studies of the diabetogenic action of streptozotocin. Proc Soc Exp Biol Med 126:201-205

27. Herzog V, Sies H, Miller F (1976) Exocytosis in secretory cells of rat lacrimal gland. Peroxidase release from lobules and isolated cells upon cholinergic stimulation. J Cell Biol 70:692706

28. Stoppiglia LF, Nogueira TA, Leite AR et al (2002) Protective effect of D-glucose, L-leucine and fetal calf serum against oxidative stress in neonatal pancreatic islets. Biochim Biophys Acta 1588:113-118

29. Vaisse C, Halaas JL, Horvath CM et al (1996) Leptin activation of Stat 3 in the hypothalamus of wild-type and $o b / o b$ mice but not $d b / d b$ mice. Nat Genet 14:95-97

30. Koito W, Araki T, Horiuchi S, Nagai R (2004) Conventional antibody against Nepsilon-(carboxymethyl)lysine (CML) shows cross-reaction to Nepsilon-(carboxyethyl)lysine (CEL): immunochemical quantification of CML with a specific antibody. J Biochem (Tokyo) 136:831-837

31. Kaji Y, Usui T, Oshika T et al (2000) Advanced glycation end products in diabetic corneas. Invest Ophthalmol Vis Sci 41: 362-368

32. Bromberg BB, Welch MH (1985) Lacrimal protein secretion: comparison of young and old rats. Exp Eye Res 40:313-320

33. Adeghate E, Ponery A, Hameed R (2005) Notes on the effect of diabetes mellitus on the morphology and function of the rat lacrimal gland. The Ocular Surface 3: S42 [Abstract]

34. Paliwal A, Srikantan AQ, Stephano PK (2005) Androgen, estrogen and thyroid hormones repress tear peroxidase gene in lacrimal gland of hamster. The Ocular Surface 3:S102 [Abstract]

35. Hofmann MA, Drury S, Fu C et al (1999) RAGE mediates a novel proinflammatory axis: a central cell surface receptor for S100/calgranulin polypeptides. Cell 97:889-901

36. Degenhardt TP, Alderson NL, Arrington DD et al (2002) Pyridoxamine inhibits early renal disease and dyslipidemia in the streptozotocin-diabetic rat. Kidney Int 61:939-950

37. Kern TS, Tang J, Mizutani M et al (2000) Response of capillary cell death to aminoguanidine predicts the development of retinopathy: comparison of diabetes and galactosemia. Invest Ophthalmol Vis Sci 41:3972-3978

38. Peponis V, Papathanasiou M, Kapranou A et al (2002) Protective role of oral antioxidant supplementation in ocular surface of diabetic patients. Br J Ophthalmol 86:1369-1373 